\title{
PROCESO DE GLOBALIZACIÓN EN GERMEN: MODO DE PRECAUCIÓN AMERICANO: RUTAS DE COMERCIO DEL ORO EL MAÍZ, LA TURQUEZA Y OTROS ARTEFACTOS CULTURALES
}

\section{GLOBALIZATION PROCESS IN GERM: AMERICAN PRODUCTION MODE: ROUTES OF TRADE IN GOLD EL MAIZ, TURQUOISE AND OTHER CULTURAL ARTEFACTS}

\author{
Mariángela Rodríguez Nicholls ${ }^{1}$ \\ (Investigadora Titular del CIESAS D.F.). \\ México
}

\footnotetext{
1 Mariangela Rodriguez mariangela.rodriguez. nicholls@gmail.com

Investigadora Titular del CIESAS D.F.. México Antropóloga tanto de la licenciatura como de la maestría $y \mathrm{del}$ doctorado. Mis publicaciones cubren un espectro amplio: desde la antropología económica hasta la cultural y simbólica, ejes de análisis que también aparecen en el mis aproximaciones diversas a la migración, que también incluye el desplazamiento de la población afro colombiana como una reedición del desarraigo original: el de la trata esclavista.
}

\section{RESUMEN}

El artículo indaga una de las vías de reflexión que se han seguido para comprender la migración que ya existía desde el sur de América hasta norte y que explica la difusión del maíz, de la turquesa, oro, plata, y productos cuyo valor estribaba en su uso ritual (Concha Spondylus), para poner unos cuantos ejemplos. Esta preocupación ha rondado por mi cabeza por muchos años. Para mi 
ha sido una ventana apasionante a través de la cual he visto la migración desde una perspectiva histórica. Enfaticé las rutas marítimas dado que las terrestres han sido mucho más trabajadas.

\section{ABSTRACT}

The article explores one of the ways of reflection that have been followed to understand the migration that already existed from the South of America to the North and that explains the diffusion of corn, turquoise, gold, silver, and products whose value lay in their ritual use (Spondiylus Shell), to put a few examples. This concern has been in my head for many years. For me it has been an exciting window through which I have seen migration from a historical perspective. It emphasizes the maritime routes since terrestrial routes have been much more worked.

\section{PALABRAS CLAVE}

Migración, rutas de comercio marítimas, globalización, modo de producción americano, etnohistoria, lenguas precolombinas, parentesco lingüístico.

\section{KEY WORDS}

Migration, maritime trade routes, globalization, American Mode of Production, Ethnohistory, indigenous languages of America, linguistic kinship.

El propósito de este artículo es mostrar la existencia de rutas de intercambio comercial, de informaciones, de personas y de artefactos culturales a lo largo de América, lo cual pone de manifiesto que no existían culturas autárquicas o aisladas sino en una relación intensa en la que los pueblos en su migración de sur a norte viajaron siempre con sus "fondos de conocimiento", como los nombra Carlos Vélez Ibáñez. Los pueblos receptores no fueron pasivos ante el contacto con los "otros" sino que resignificaron diversas prácticas culturales en ese proceso cultural que implica una creación continua.

No hago una exposición exhaustiva de las rutas de comercio, pero sí tomo ejemplos paradigmáticos que muestran claramente a los lectores lo que ha sido caracterizado como un Modo de ProducciónAmericano. Enfatizo el caso de Suramérica y su relación con el occidente de México, porque he estudiado la migración actual de los purépechas hacia los Estados Unidos; esta antigua conexión cultural requirió de tratamiento aparte. Pero además incluyo el ejemplo de la influencia mesoamericana en el suroeste de los Estado Unidos para completar una visión panorámica de América y diversas rutas de interconexión.

Comienzo este artículo trayendo a colación la discusión tan en boga en los setenta acerca de si era posible encontrar rasgos del modo de producción asiático en América Latina . Sobre este tópico corrió mucha tinta debajo de los puentes de la antropología. Bartra hablo del Modo de Producción Tributario2; Palerm de Modo de Producción Hidráulico3; Matos de Modo de Producción Americano. ${ }^{4}$ y Eric Wolf complemento dos caracterizaciones al retomar uno de los ejes y pilares de la antropología, el parentesco, lo cual lo llevó a reflexionar sobre el poder en esta esfera de inclusiones y exclusiones y el tributo. ${ }^{5}$

La conceptualización que hace Eduardo Matos me parece la más acertada dado que tiene una perspectiva integral de los procesos económicos sociales y culturales de América. Creo que el valor que presentan estas reflexiones es el

\footnotetext{
$2 \quad$ Véase, Roger, Bartra, "El Modo de producción asiático en las sociedades pre capitalistas", en J. Chesnaux. et.al. El Modo de Producción asiático, México. Ed. Grijalbo Col.70. No.42-. 1969.

3 Véase, Ángel, Palerm, "Una defensa del Modo asiático de Producción según Marx y Witfogel", México. UIA. Comunidad. No.23.pp.31 - 46,1970.

4 Véase, Eduardo, Matos, Moctezuma, "Mesoamérica" en Historia antigua de México, México, Vol. I pp. 49-73, 1994.

$5 \quad V e ́ a s e$, Eric Wolf, Europa y la gente sin historia, Fondo de Cultura Económica, F.C: E. México, 1987.
} 
cuestionamiento profundo que desde la historia puede hacerse a la antropología basada en la visión estática del presente etnográfico, a modo de una fotografía tomada en el momento en el que el etnógrafo hizo el trabajo de campo.

Uno de los aspectos centrales para la caracterización del Modo de Producción Americano es la consideración del desarrollo de las fuerzas productivas, hecho que impacta la productividad del trabajo. Ésta depende del desarrollo (tecnificación) de los medios de producción; de la división social del trabajo y de las condiciones del entorno material. En cuanto a la división social del trabajo es importante destacar que esta condición da lugar a la existencia de clase sociales, ciudades y obras hidráulicas, hechos que permiten no sólo la reproducción social de la fuerza de trabajo sino también la generación de un excedente que se incrementa mediante el tributo de otras sociedades y el desarrollo de formas estatales; para garantizar que dicho tributo fuera efectivo.

Las sociedades indígenas combinaron el trabajo productivo con el solidario del tequio o la mano vuelta en las unidades familiares organizadas sobre la base del parentesco.

Para establecer qué tanto desarrollo de las fuerzas productivas tuvieron las sociedades americanas, uno de los datos más relevantes lo constituye las obras hidráulicas que permitieron el riego y en consecuencia la alta productividad de las cosechas o el establecimiento de islas flotantes para cultivos de alta rentabilidad tal es el caso de las chinampas. ${ }^{6}$

Eduardo Corona propone con certeza en concordancia con Eduardo Matos que el continente americano conformó un modo de producción correspondiente; en tanto entre el sur como en el norte se desarrolló una compleja $6 \quad$ Véase, Teresa Rojas, Rabiela, La agricultura chinampera compilación histórica, núm. 7 de la colección Cuadernos Universitarios, Serie Agronomía, Universidad Autónoma de Chapingo, Dirección de Difusión Cultural, 1983. red de relaciones sociales, políticas, económicas e ideológicas ${ }^{7}$

Para Matos el modo de producción americano tendría dos vertientes evolutivas: 1.- La de cazadores y recolectores que son aquellos que se dedicaron a la domesticación e hibridación de plantas como la yuca, la batata. 2.- La de los agricultores.

A la primera correspondería una forma de organización social clánica e igualitaria y a la segunda una forma de organización clánica cónica. Éstos (los agricultores), van desplazando a cazadores y recolectores hacia áreas de refugio. Esta época coincide con el surgimiento de Estados tanto en Suramérica como en Mesoamérica.

De acuerdo con mi punto de vista la caracterización del Modo de Producción Americano es muy importante porque Matos considera un mayor número de aspectos que rebasan las concepciones que toman sólo la extracción de excedente por vías extra económicas y/o la construcción de obras hidráulicas.

Enfatizaré el desarrollo metalúrgico como una de las características centrales del vinculo Andes Occidente de México para lo cual retomo algunos de los planteamientos de Eduardo Corona con relación a dicho desarrollo.

Primero fue el oro, luego el cobre, con posterioridad el estaño; aleaciones de cobre con estaño en el sur y de cobre con arsénico en el occidente de México.

Esta tradición llego tardíamente a Colombia y Panamá (500 d.c) y es la época en la que aparece en Mesoamérica, con técnicas de laminado, martillado, cera perdida y filigrana utilizada por los pertenecientes a la cultura tairona. Ésta se

$7 \quad$ Véase, Eduardo, Corona, "La integración de los pueblos mesoamericanos en el Modo de Producción Americano" en Pueblos de América,org, México, 2010, p11. 
ubicaba en la Sierra Nevada de Santa Marta, macizo montañoso aledaño al mar Caribe cuyas comunidades vivían bajo el mando de un jefe supremo. La manera de vivir de los tayronas se caracterizaba por viviendas enclavadas en medio de escalinatas diques. Vivían del cultivo del maíz, frijol, yuca y batatas. La arqueología de la zona ha revelado un trabajo en oro muy fino que migró por el Atlántico desde Colombia a la zona maya y por el Caribe hacia Cuba y la península de Yucatán.

En Colombia también los chibchas se destacaron por el uso del oro. Éstos ocupaban cuencas altas en lo que corresponde a Cundinamarca y Boyacá a sus gobernantes se les llamaba Zipas y Zaques y la población vivía del cultivo de la papa, maíz y quinoa. Se extraía tributo de los llamados comuneros, cambiaban productos textiles por el oro que usaban de forma ornamental y ritual. Las redes de intercambio eran para entonces muy complejas y daban lugar a la generación de un importante excedente. Los indígenas mojos del sur de Bolivia por ejemplo, intercambiaban con las mesetas andinas. Éstos iban hasta la zona de los Aymara para cambiar plumas y telas de algodón por instrumentos de metal.. Esta ruta fue muy importante porque fue la vía a través de la cual llegaron los metales preciosos y el cobre de los Andes hasta el rio Paraguay. Esta ruta despertó la codicia de los conquistadores pues a sus oídos llegó la existencia del Reino del Gran Mojo. La joyería inca de oro llegó también al río Ucayali como parte del intercambio entre grupos de la montaña tropical. Los incas nunca pudieron conquistar a los jibaros que poseían un territorio rico en este metal precioso.

Por otra parte, al norte de Chile y Argentina se propagó la cría de llamas que los atacameños intercambiaban por pescado y sal. Entre picunches y diaguitas los incas buscaron metales preciosos: oro, cobre y plata.

En Colombia no hubo un desarrollo de fuerzas productivas tal que permitiera el esplendor de la sociedad inca, maya o azteca.

Después de la caída de Tenochtitlán en manos de los españoles en 1521, éstos se encaminaron hacia lo que hoy se conoce como Michoacán en busca de metales preciosos: oro, plata y cobre. Esta zona habitada por los indígenas purépechas fueron llamados de manera equívoca tarascos por los españoles que quiere decir extranjero. Esta confusión se deriva de que la nobleza purépecha propicio el matrimonio de sus hijas con los españoles y llamaba a éstos tarascos (yernos). Por otra parte los conquistadores usaban la misma denominación para nombrar a los suegros y de esta manera convalidar la relación. La zona purépecha no se circunscribía sólo a Michoacán incluía a Guanajuato, Querétaro, Guerrero y parte de Jalisco.

Tan pronto como se dio el contacto los españoles empezaron a darse cuenta de lo distintos que eran los purépechas al resto de los indígenas vecinos. Su extraña lengua no tenía similitud con ninguna de las que se hablaba en México; su atuendo también era distinto; eran cazadores y recolectores; su calendario era incipiente y rústico; eran excelentes orfebres, trabajaban el oro, la plata y el cobre con los cuales construían armas y herramientas. Esto constituye una diferencia fundamental ya que el resto de los grupos indígenas usaba la obsidiana. Tampoco sus templos tenían ningún parecido con los mesoamericanos.

La manera como se tallaron las piedras y la forma de colocarlas en las yácatas purépechas (templos circulares dispuestos en línea sobre un basamento rectangular); que pueden verse en Zintzuntzan no se parecen a las construcciones mesoamericanas, muy por el contrario tienen reminiscencias andinas, por ejemplo: en los cortes de ocho facetas que se observan en las piedras que las integran. ${ }^{8}$ Eduardo Williams también habla de las conexiones que se han 8 Véase, Vicent H. Malmström, "Geographical Origins of The Tarascans” en Geographical Review, Vol. 85, No. 1, January, 1995, pp.12-15. 
establecido entre quechuas y tarascos y hace referencia a la conexión metalúrgica que se puede establecer entre estos pueblos con relación al trabajo del cobre, bronce y a las pipas de cerámica encontradas en las excavaciones. Y según el mismo autor puede encontrarse un parecido con los hallazgos arqueológicos de Kaui en Hawai.

Arturo Oliveros se pregunta si es viable afirmar que los purépechas vinieron de América del Sur. Esto no solamente es una premisa posible sino profundamente realista ya que además de los elementos antes señalados, las costumbres funerarias del Occidente de México como las que pueden observarse en el Opeño, Michoacán, muestran enormes semejanzas con las del área andina. ${ }^{9}$

Así pues la metalurgia del occidente de México tuvo su origen en los Andes septentrionales. Para hacer esta precisión se tomó en cuenta la carta escrita por Rodrigo de Albornoz a Carlos $V$ en la que se menciona la aparición de mercaderes venidos del sur y que hacían sus intercambios en Zacatula. Traían ropa tejida, vestidos y la metalurgia. Se llevaban la concha Spondylus que era muy apreciada porque se utilizaba en rituales propiciatorios de la buena cosecha.

José Beltrán a su vez encontró en Punta Mita, Nayarit un yacimiento prehispánico de pescadores de Spondylus, pesas de bucear y anclas asociadas a la cultura Manteña que es la tradición más antigua; lo cual sugiere un vinculo indiscutible entre estos dos complejos culturales $^{10}$

Es importante mencionar la importante extensión que ocupaba Mesoamérica: iba desde Teotihuacán hasta Kaminaljuyú y Tikal en el Petén y que además era una zona rica en $9 \quad$ Véase, Arturo, Oliveros, Hacedores de tumbas en el Opeño, Jacona, Michoacán, El Cologio de Michoacán, 2004.

10 Véase, José Beltrán, "Los pescadores de Punta Mita, Nayarit", ponencia presentada en el 49 Congreso Internacional de Americanistas, Quito, Ecuador, julio de 1997. intercambio comercial. Teotihuacán tenía a la llegada de los españoles una tecnología agrícola muy desarrollada con obras hidráulicas de gran calado. Se producían utensilios de obsidiana. Cuando este centro urbano colapsó, Tula Tula pasó a ser el centro cultural del Valle de México. Aquí se aglutinaban guerreros, comerciantes cultivadores y sacerdotes.

\section{ARQUEOLOGÍA}

Han sido estudiadas una red de relaciones que vinculan a Mesoamérica con América del Sur. Eduardo Corona menciona diversas evidencias arqueológicas como las siguientes: formas y diseños que se localizan en Mesoamérica y que en apariencia son más comunes en las tradiciones andinas o macro quechuas. Como por ejemplo: vasijas de asa de canasta, las de vertedera, o antropomorfas con asa vertedera, decoradas en negro, que aparecen en las regiones de la Cuenca de México, en Michoacán desde el Formativo hasta el Postclásico.

Piña Chán sostiene la hipótesis de que este tipo de cerámica se encuentra en Venezuela desde donde pasó a la Costa del Perú y de ahí a Oaxaca, Michoacán, Guerrero, Colima, Sinaloa, Jalisco, es decir; a todo el Occidente de México y que se conservan hasta el momento de la conquista. ${ }^{11}$

Por otra parte Lumbreras, ha localizado en el norte de la región andina: En Panamá, Colombia, parte de Venezuela y del Ecuador diseños de tradición cerámica mesoamericana. También explica la existencia de un intercambio comercial intenso entre estas dos áreas culturales a partir de lo encontrado en las excavaciones: conchas de tipo Spondylus a cuyo uso y valor hice referencia en líneas anteriores.

De igual manera se ha encontrado gran similitud en la cerámica de Panamá, Colombia, Venezuela y Ecuador con la encontrada en

11 Véase, Eduardo Corona, "La integración de los pueblos mesoamericanos...", p.11. 
el área Mesoamericana. Para Lumbreras las coincidencias existentes entre el área andina y Mesoamérica son fruto de un intenso intercambio marítimo entre el occidente de México y el área andina. Esto es de tal manera importante que el autor piensa que visto este problema con rigor permitiría hablar de procesos de colonización de unos grupos sobre otros. Este hecho implica, la creación de nuevas culturas y esto es lo que abre la posibilidad de la existencia de un modo de producción común, un modo de producción

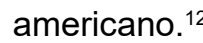

Algunas figurillas que se observan en el museo universitario de Cali Colombia, representan a dioses mesoamericanos vinculados con la fertilidad y el inframundo; en las costas del pacifico cercanas a Cali también se han encontrado cerámicas con esas mismas características; de igual forma se encuentran cerámicas y hombres felinos que aluden claramente a un parentesco entre el área andina y Mesoamérica. ${ }^{13}$

\subsection{LA LEYENDA DE LA MIGRACIÓN}

Se cuenta que los evangelizadores empezaron a recopilar la tradición oral del enigmático pueblo purépecha. De acuerdo con ésta, purépecha quiere decir: "los recién llegados". Los evangelizadores inquirieron a los ancianos acerca de dónde procedían y cuándo habían venido. Éstos al no tener lengua escrita, no tenían manera de dejar un registro por tanto dependían de la historia oral y los ancianos dijeron a los evangelizadores que procedían del sur.

Según E.R, Craine and R.C,Reindorp en el llamado Lienzo de Jucutácato se registra el lugar de origen del pueblo purépecha, muy al sur, en Cuzco Perú y que de ahí vinieron a su

$12 \quad$ Véase, Luis Guillermo Lumbreras, Arqueología de la América Andina, Editorial, Batres, Lima Perú. 1981, pp. 210-212.

13 Ibid, Chavín de Huantar en el Nacimiento de la Civilización Andina, Instituto Andino de Estudios Arqueológicos, Ediciones Indea, Lima, 1989. actual Michoacán; por la boca del gran río que los españoles supusieron que se trataba del Orinoco ${ }^{14}$. Después el periplo continuó por el mar y llegando al Golfo de México por Oaxaca hasta Michoacán. Cuando se les preguntó cómo hicieron para cruzar las tierras de mortales enemigos como los aztecas, respondieron que tenían una muy buena relación con ellos y que habían venido juntos. Me interesa en este artículo, explorar la hipótesis basada en el Lienzo de Jucutácato que plantea que los purépechas migraron desde el Sur por el río Orinoco y se asentaron en Michoacán. Quisiera rescatar esta relación entre América del Sur y el occidente de México, ya que es una historia que ha sido estudiada pero poco conocida. El lienzo mencionado y la Relación de Michoacán son los dos documentos históricos más importantes.

Por otra parte diversas fuentes han manejado una hipótesis contraria y es que provenían de las siete cuevas de Chicomostoc, que eran parte de los Chichimecas primos de los Aztecas. Estas versiones son inciertas en tanto los españoles no tenían un conocimiento muy certero de la geografía.

Sobre la hipótesis de su origen chichimeca, hay una salvedad muy importante: esta cultura no trabajaba la metalurgia con tan alta tecnología. Parece ser que vincular al pueblo purépecha con los chichimecas resulta una visión muy cándida.

\subsection{LENGUA}

Hay que reseñar otra aproximación hipotética: las evidencias lingüísticas que vinculan a la lengua purépecha con la chibcha de Colombia y con la quechua, ambas lenguas habladas en Sudamérica. Muy frecuentemente se menciona a Mauricio Swadesh autor que estableció el vínculo lingüístico entre tarascos y quechuas. Es de hacer notar como ejemplo, que en quechua la palabra taita se convierte entre los tarascos

14 Craine, E. R., and R. C. Reindorp, (eds.), The chronicles of Michoacán, Norman: University of Oklahoma Press, 1970. 
en tata y wawa en quechua para designar niño o niña entre los tarascos se convierte wa. ${ }^{15}$ . Este autor clasificó a los tarascos dentro de la familia lingüística macro quechua y dentro del grupo chibcha lo hizo Greenberg ${ }^{16}$. Todas las hipótesis lingüísticas han resultado controversiales en tanto se dice que los autores siguieron su intuición encontrando similaridades sonoras pero no hicieron una fonología histórica que es la premisa fundamental para probar el parentesco entre idiomas. Y se obvia que el mismo Swadesh también encontró parentesco lingüístico del purépecha con el zuñi de América de Norte y con el maya, mixe y totonaca. Lo que finalmente estaría mostrando Swadesh es la profunda red de intercambio existente entre los pueblos prehispánicos de toda América.

La cantidad de oleadas migratorias provenientes del área andina hasta el año 1500 pueden ser una explicación plausible de lo extendida que estaba la población purépecha en México.

Recordando que los límites geográficos establecidos entonces resultan muy inciertos, como se dijo en líneas anteriores.

Además del origen sureño de los purépechas hay que considerar que poblaron el lago de Pátzcuaro como resultado de una migración interna. Se dice que migraron por el pacifico hasta esta región. Según el propio López Austin, la expansión de los purépechas se explica en parte en la medida en que Titacame y los suyos, cazadores y recolectores procedentes de Zacapu-Naranja arribaron al norte del lago, posteriormente se relacionaron con los agricultores y recolectores de Jarácuaro. Sobre la base de relaciones de alianza y guerra se hacen fuertes los purépechas y establecen sus señoríos en Tzintzuntzan, Ihuatzio y Pátzcuaro. Ensancharon y fortalecieron sus dominios

$15 \quad$ Véase Mauricio Swdesh, "Un nexo prehistórico entre quechua y tarasco", en Anales, Instituto Nacional de Antropología e Historia, Época séptima, Tomo 1, 1967-1968, México, pp. 127-131.

16 Véase, Greenberg JH, Language in the Americas, Stanford University Press, Stanford, 1987. gracias a que poseían oro, cobre y piedras preciosas, entre otras cosas. Frente a este fortalecimiento los mexicas libraron grandes batallas para detener el paso de los purépechas. Éstos jamás fueron conquistados.

Según Corona es importante considerar que hubo migración y relación establecida entre purépechas y quechuas y que ésta explicaría la presencia del maíz cacahuazintle en Perú, y figuras con deformación supra craneana y mutilación dentaria, prácticas procedentes de Suramérica que puede observarse en Mesoamérica. $Y$ cabe también mencionar la presencia en ambas tradiciones culturales del jaguar como símbolo dominante.

\subsection{VESTIDO}

Patricia Rieff Anawalt encontró que el vestido e hilado en el occidente de México tiene enorme semejanza con el tejido y vestido de la costa del Ecuador en el Formativo Tardío ${ }^{17}$

Corona caracteriza las relaciones entre el sur y norte de América como un Modo de Producción Americano basado en datos arqueológicos y etnohistóricos a los que ya he hecho referencia; a estas relaciones las llama tradiciones culturales lo cual habla de una caracterización más compleja que tomar sólo en consideración rasgos aislados. Esta postura es muy interesante ya que intenta ir más allá en la interpretación, viendo un entramado de significación de matriz común, con diferentes y particulares historias y por supuesto con diferencias étnicas pero no estructurales. Este mismo autor reseña el hecho de que existen más de sesenta plantas que se han hibridizado: por ejemplo maíz, frijol, calabaza, yuca dulce, aguacate, papaya, zapote y que se han utilizado en las tres sub áreas del continente: Mesoamérica, Chibcha y Andes.

$17 \quad$ Patricia Rieff Anawalt, "Traders of the Ecuador Littoral",en Archaqueology, Vol. 50, No 6, NovemberDecember, 1997, p 45. 
También se encuentran tanto en Suramérica como en Centroamérica las mismas especies de mamíferos, insectos y reptiles con las que complementaban su dieta; algunos como los camélidos desaparecieron en Mesoamérica; en Suramérica siguen siendo importantes como alimento y materia prima para el vestido.

Por otro lado están las chinampas, los sukakoyos (islas flotantes), a las cuales he hecho mención al comienzo de este artículo, con las cuales pudieron obtener hasta cuatro cosechas de maíz al año, ampliando la capacidad productiva, y por tanto la generación de excedente; lo cual permitió el desarrollo de centros ceremoniales, ciudades, y la aparición de una categoría social: los sacerdotes como personas especializadas libres del trabajo directo de la producción.

\subsection{METALURGIA}

Llama la atención también otro vínculo importante, la forma como trabajaron la minería: el oro martillado y la técnica de la cera perdida, en el área andina. $Y$ con posterioridad el cobre y bronce como objetos de ornato personal. Esta presencia de metal en Mesoamérica no es producto de un desarrollo propio sino que tiene que ver con las rutas de comercio y con la navegación por el Pacifico; hechos que pueden además explicar la presencia del tabaco y cacao en el área andina.

Toda esta tradición cultural suramericana se preservó en el occidente de México por el uso de la metalurgia y piedras preciosas de ornato identificadas con los Uacusecha o clase dirigente quienes desarrollaron la forma estatal de los tarascos equivalente a los pillis de la sociedad mexica. (Los macehuales o los pobres dentro de esta misma sociedad correspondieron a los purépechas o "gente del común" entre los tarascos).

Es interesante tomar en consideración que la Relación de Michoacán describe entre los muchos objetos de ornato usados en la zona, aretes en forma de tortugas y ranas de clara influencia colombiana.

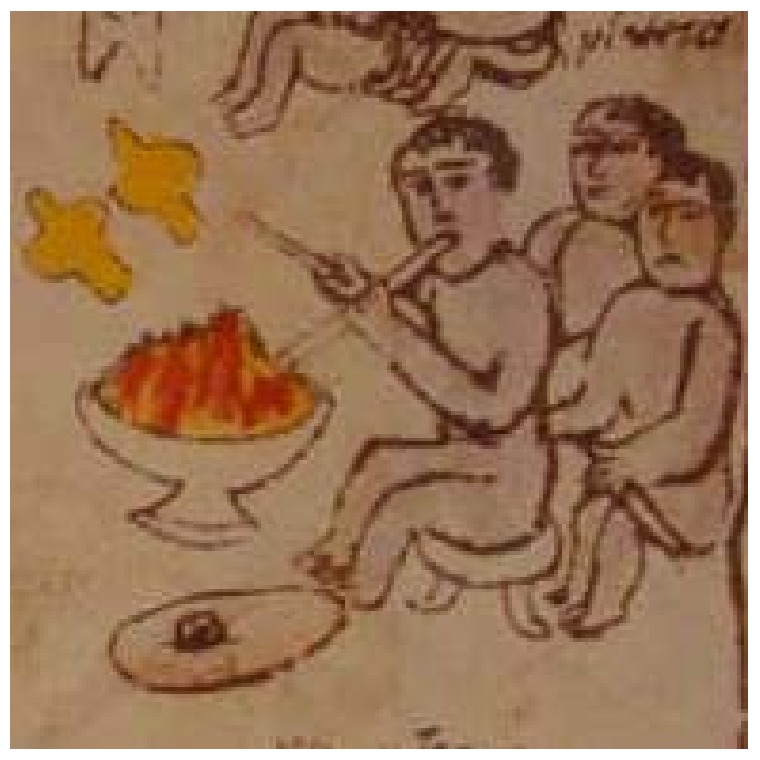

Relación de Michoacán

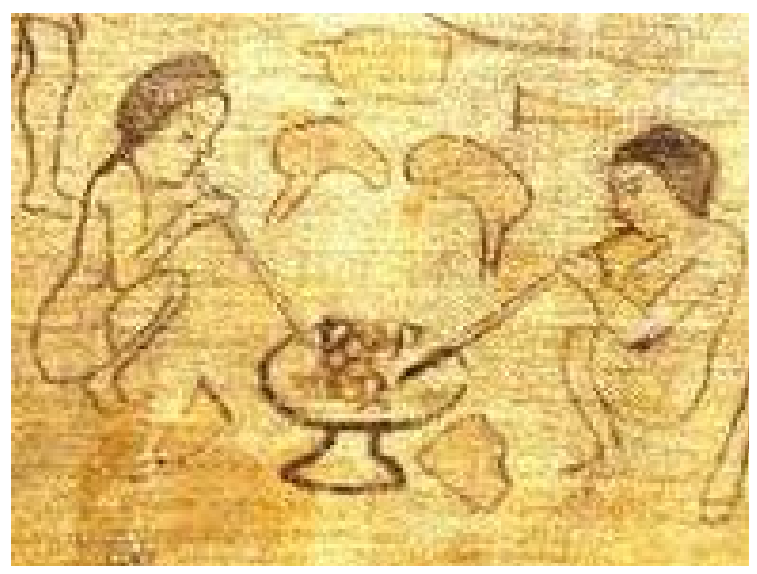

Códice Mendoza

Lienzo Jucutacáto

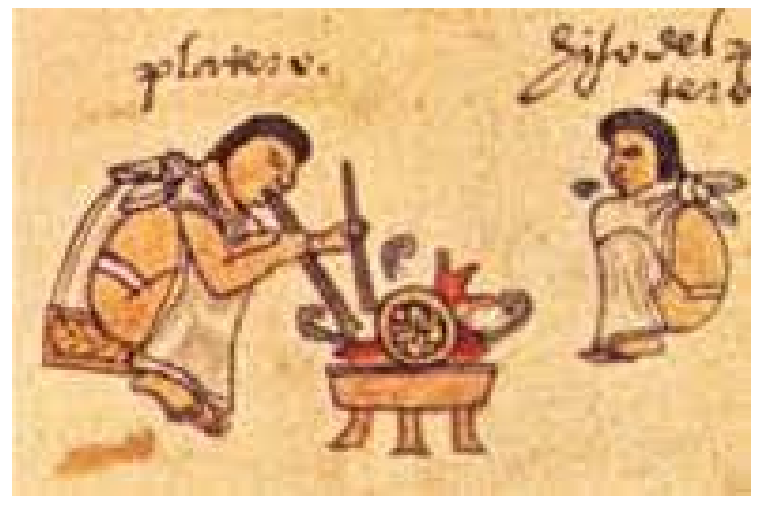


La metalurgia tarasca está totalmente emparentada con los Andes no sólo en cuanto técnica sino en cuanto a la función de los artefactos; el empleo de bronce y de cobre en hachas, pinzas para depilar, es una tradición de Perú y Bolivia lo mismo puede decirse de las ideas en cuanto a la función social de los objetos que fueron importadas de Ecuador. Humboldt describe la fundición de la plata en Quito de la siguiente manera: los antiguos habitantes de Quito fundían los minerales de plata estratificándolos con carbones y soplando el fuego con cañas grandes de bambú muchos indios se colocaban en círculo alrededor del hoyo que encerraba el mineral de manera que las corrientes de aire que salían de muchas cañas a la vez avivaban el fuego. Este procedimiento se da tanto en Ecuador, como en Colombia y México.

\subsection{COSTUMBRES FUNERARIAS}

Otra tradición compartida es el uso de cinabrio para cubrir a los difuntos, el enterramiento en las tumbas de tiro como es el caso de las localizadas en el Opeño Michoacán (Olivera 1970).

Por parte de numerosos investigadores y desde hace mucho, se encontraron semejanzas entre el occidente de México y el norte de Sudamérica, para esta observación fueron claves las costumbres funerarias propias de esta zona de México, Ecuador y Colombia; las similitudes no solamente se establecieron a partir de las tumbas, sino por la cerámica que las acompañaban.

\subsection{RUTAS DE COMERCIO}

Según Corona habría varias rutas de comercio: desde Colombia a Cuba y de ahí hacia la península yucateca por vía marítima; por vía terrestre desde Colombia, Panamá, Nicaragua hacia Guatemala cruzando la zona maya pasando por el altiplano de México. Otra es la posibilidad de que de Perú vinieran a las costas de occidente y de ahí se difundieran tales tradiciones culturales por todo el occidente de México.

Dorothy Hosler quien ha investigado de manera muy rigurosa la procedencia andina de la metalurgia del occidente de México señala: no sólo la existencia de cascabeles, agujas de coser, pinzas de depilar y argollas que han sido encontradas en la tumbas de tiro sobre los cadáveres, tienen una clara procedencia andina porque, aparecieron en el occidente de México siglos después de haber sido halladas en excavaciones tanto en Perú como en el Ecuador y Colombia. Dice la autora que en una Relación del siglo XVI escrita por Salomón Jerez que los manteños eran magníficos navegantes que recorrían el océano pacifico en canoas y que fueron vistos por los españoles portando los objetos mencionados que eran usados para intercambiarlos por concha Spondylus en el occidente de México. ${ }^{18}$ Eric Wolf también menciona que los manteños fueron excelentes navegantes y que probablemente tuvieron relación con Mesoamérica. Esto lo colige de que los españoles a su llegada capturaron una gran canoa de madera con velas y cabina en la iban veinte hombres con treinta toneladas de mercaderías de lujo.

18 Véase, Dorothy Hosler, "Los orígenes andinos de la metalurgia del occidente de México", Ponencia presentada en $49^{\circ}$ Congreso Internacional de Americanistas, Quito, Ecuador, 1997. Tomo en este articulo el mapa elaborado por la autora con los que ilustra sus planteamientos. 


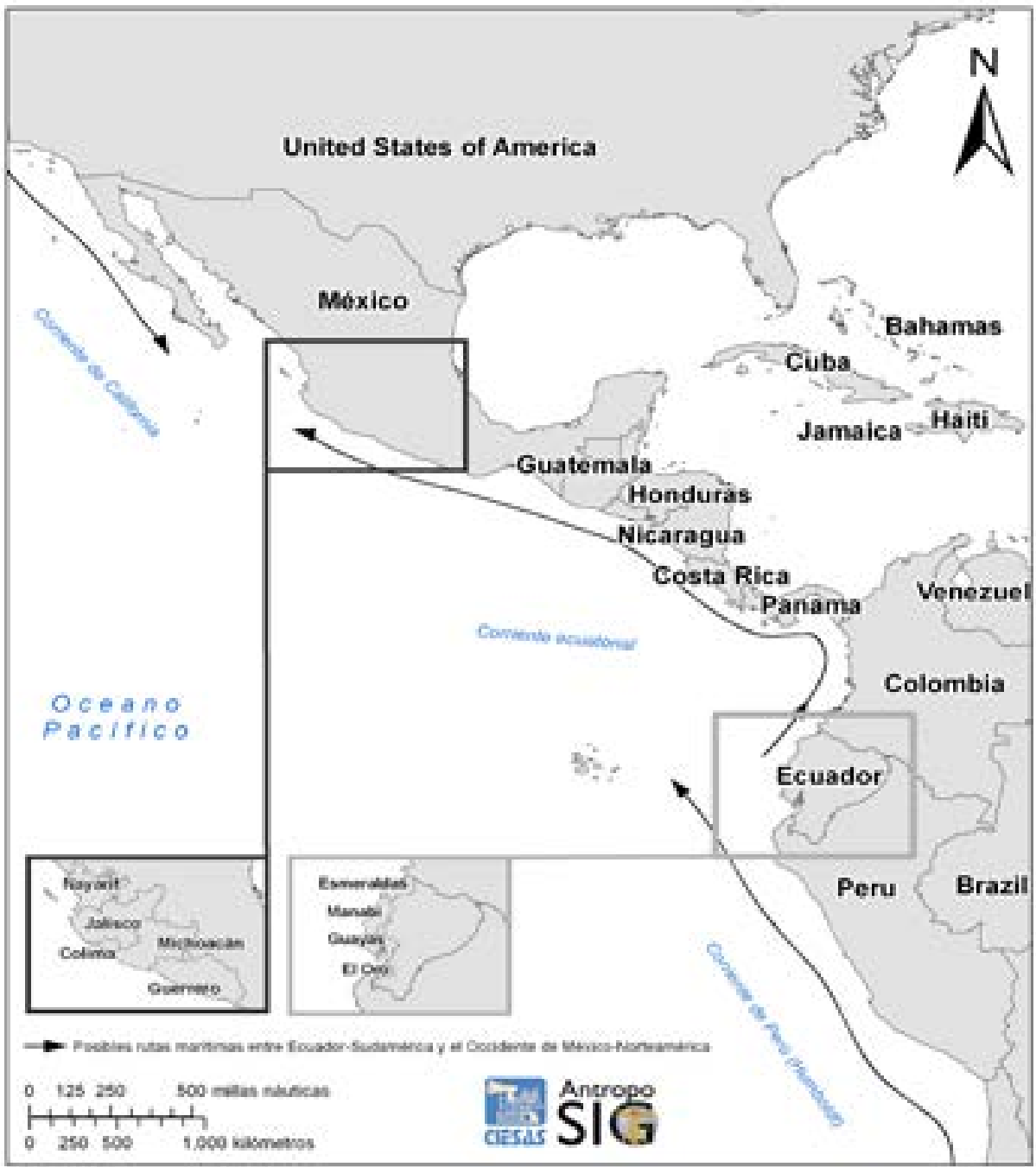

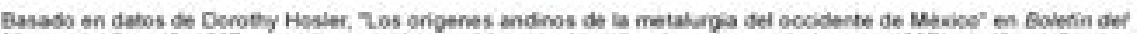

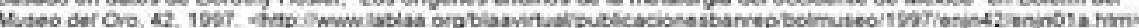

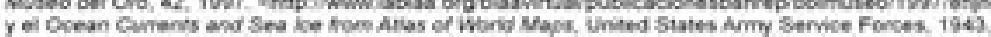

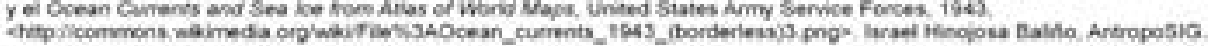

Rutas de comercio marítimo

Hay dos razones de carácter geográfico que explican el por qué esta migración pudo ser posible: las bahías naturales y las corrientes marinas que facilitaron el viaje en particular en el sentido sur - norte, donde tales corrientes costeras vienen desde lugares tan lejanos como Chile. El retorno requiere navegar a mayor distancia de la costa a fin de aprovecharlas en sentido contrario norte- sur ${ }^{19}$. En resumen, los

19 Véase, Luis Torres Montes y Francisca Franco Velásquez, "la metalurgia tarasca producción y uso de los metales en Mesoamérica", en Temas Mesoamericanos, SoniaLombardo y Enrique Nalda, (coord.), México, Colección Varios, Instituto Nacional de Antropología e Historia, 1996. vientos entre la costa norte de Perú y Ecuador favorecen la navegación de sur a norte. $Y$ éstos, en el occidente de México la favorecen en sentido inverso. Dewuan ha calculado que el viaje redondo de aproximadamente de $7000 \mathrm{~km}$ de Ecuador a México en una balsa de vela debió durar cuatro meses ${ }^{20}$. Para completar el periplo pasaban seis meses en México esperando que vientos y corrientes les fueran favorables.

\footnotetext{
20 Vorgelegt von Sarah Albiez Wieck, "Contactos exteriores del Estado Tarasco: influencias desde dentro y fuera de Mesoamérica", Inaugural-Dissertation zur Erlangung der Doktorwürde de Philosophischen Fakultät Der Rheinischen Friedrich-Wilhelms-Universität zu Bonn, Boon, 2011, pp. 373-377.
} 
Según Jorge G. Marcos, el sistema de intercambio que siguieron los pobladores de los Andes con el occidente de México ya contenía en ciernes, gérmenes de la globalización. A estos complejos comerciales los llamó "Mullo"21.

De acuerdo con Lumbreras la producción de herramientas de metal está asociada a elementos de prestigio y a la existencia de clases sociales que permitieron a su vez el desarrollo de ciudades y de Estados. ${ }^{22} \mathrm{Y}$ yo agregaría la generación de excedente producto del tributo.

\section{1.-8 OTRA CONEXIÓN IMPORTANTE}

Lo planteado hasta aquí, puede ser comparado con lo analizado por Carlos Vélez Ibáñez en su libro en cuyo trabajo se muestran las interrelaciones que había entre el norte de México con el suroeste de los Estados Unidos demostrando que el intercambio ha sido permanente y de sur a norte. ${ }^{23}$ Tomo como ejemplo los casos del maíz y de la turquesa que él reseña para lo cual se remite a dicho vínculo.

Mesoamérica cuya impresionante extensión iba desde Teotihuacán hasta kaminaljuyú y Tikal en el Petén era un área muy rica en intercambio comercial. Teotihuacán contaba a la llegada de los españoles 2500.000 habitantes aproximadamente. Tenía una tecnología agrícola muy desarrollada con obras hidráulicas de gran calado. Se producían aquí utensilios de obsidiana ya que contaban con canteras de este material. Cuando este centro urbano colapsó, Tula pasó a ser el centro cultural del Valle de México. Tula se convirtió entonces en el centro que aglutinaba a guerreros, comerciantes, cultivadores y sacerdotes llamados toltecas. Pero

21 Jorge G. Marcos, Los pueblos navegantes del Ecuador prehispánico, ediciones ABYA-YALA, Quito, 2005.

22 Véase, Luis, G. Lumbreras, Visión arqueológica del Perú Milenario, Editorial Batres, Lima, Perú, 1990.

23 Véase, Carlos Vélez Ibáñez, Border Visions, Mexican Cultures of the Southwest United States, University of Arizona Press, 1996. El autoir en este libro desarrolla una idea que había esbozado E. Wolf, Europa y la gente sin historia, Fondo de Cultura Económica México, 1987. además se cree según el autor, que se convirtió en el principal centro de comercialización de minerales tanto en Mesoamérica como en Casas Grandes, situado en la mitad de Chihuahua y La Quemada en la parte central de Zacatecas; ésta última considerada el vínculo más importante con Tula. Hay en los intercambios multitud de elementos uno muy importante Desde Casas Grandes el intercambio comercial con los hohokam y mogollón, se hizo sirviendo Chalchihuites como sitio para transferir a Tula la turquesa de Nuevo México extraída de la mina de Cerrillos. La turquesa fue muy importante ya que fue el mineral escogido por las elites del Gran Suroeste de los Estado Unidos y de sus contra partes mexicanas del norte y por los señores de toltecas de Tula. De acuerdo con Dobins los mesoamericanos importaron turquesa de Cerrillos, de Gleason en el suroeste de Arizona,y de Cerbat Mountains en Mojave en el área de California. ${ }^{24}$

\subsection{OTRA MIGRACIÓN}

El autor piensa que hubo una migración del sur al norte ya que sólo así se explica que los hohokam tuvieran una gran tradición cerámica, que utilizaran técnicas de irrigación provenientes del centro de México. Migraron como lo han hecho siempre: llevando consigo "sus fondos de conocimiento", que explican por qué desarrollaron formas hibridas del maíz que adaptaron al entorno árido. Esta reflexión del autor le daría una ruta de continuidad a la concepción de que las rutas de intercambio comercial vincularon el sur con el norte como uno solo. Carlos Vélez retoma la pregunta que se hace Dobyn's con respecto a: ¿ Con qué se encontraron los españoles al momento del contacto? El ejemplo del maíz es importante porque es un elemento cuya producción y consumo unifica a toda América. En el caso de los Estados Unidos las rutas de éste cubrirían

24 Véase, Henry Dobyns, "Trails to Casa Grande", Casa Grande Valley,Histories, Casa Grande Valley Historical Society, pp.3-26. 
las cuatro áreas culturales: Hohokam, Mogollón Anasazi del Cañón del Chaco y Mesa Verde, con lo cual estarían incluidas Arizona, Nuevo México, Utah y Colorado relación establecida por otro autor: Hauri ${ }^{25}$ Para este autor tuvo lugar a través del Valle del rio Gila (en el presente Florence Arizona) Su reflexión se amplía cuando dice que ni los hohokam, ni los anasazi ni los mogollón provenían de Mesoamérica, sino ya habitaban el suroeste de los Estados Unidos dependiendo de formas arcaicas de agricultura y que fueron influenciados en forma diferencial por los migrantes mesoamericanos.

De aspectos importantes provenientes en el centro de México hace referencia también al culto de Quetzacoat//Tezcatlipoca, dioses de la luz y de la oscuridad. En excavaciones arqueológicas se encontraron espejos símbolo de esta deidad en Jalisco, Nayarit, que como serpiente emplumada aparece en Teotihuacán y hasta en la cultura maya de México y Guatemala.
Otra cuestión de influencia mesoaméricana que puede encontrarse en el suroeste de los Estados Unidos son las pirámides de tierra mucho más rudimentarias que las del centro de México.

El juego de pelota, la creencia en un inframundo y super mundo. "Dicho juego simbolizaba la lucha entre el bien y el mal encarnados en los míticos hermanos Quetzalcóatl y Tezcatlipoca. Este juego muy probablemente servía para diluir tensiones entre los pueblos como una forma simbólica en la que las confrontaciones se evitan. Esto me lleva mi trabajo de campo entre los purépechas donde el juego de basket ball es tan importante y fundamental para la sociabilidad de los pueblos de la Cañada por ejemplo. Como una forma trasmutada de aquella costumbre ancestral, pero secularizada, pero con algunas funciones similares.

Se menciona también y esto vincula al suroeste de los Estados Unidos con el occidente de México (norte de Michoacán, Guanajuato, Aguas Calientes y el sur de Zacatecas).

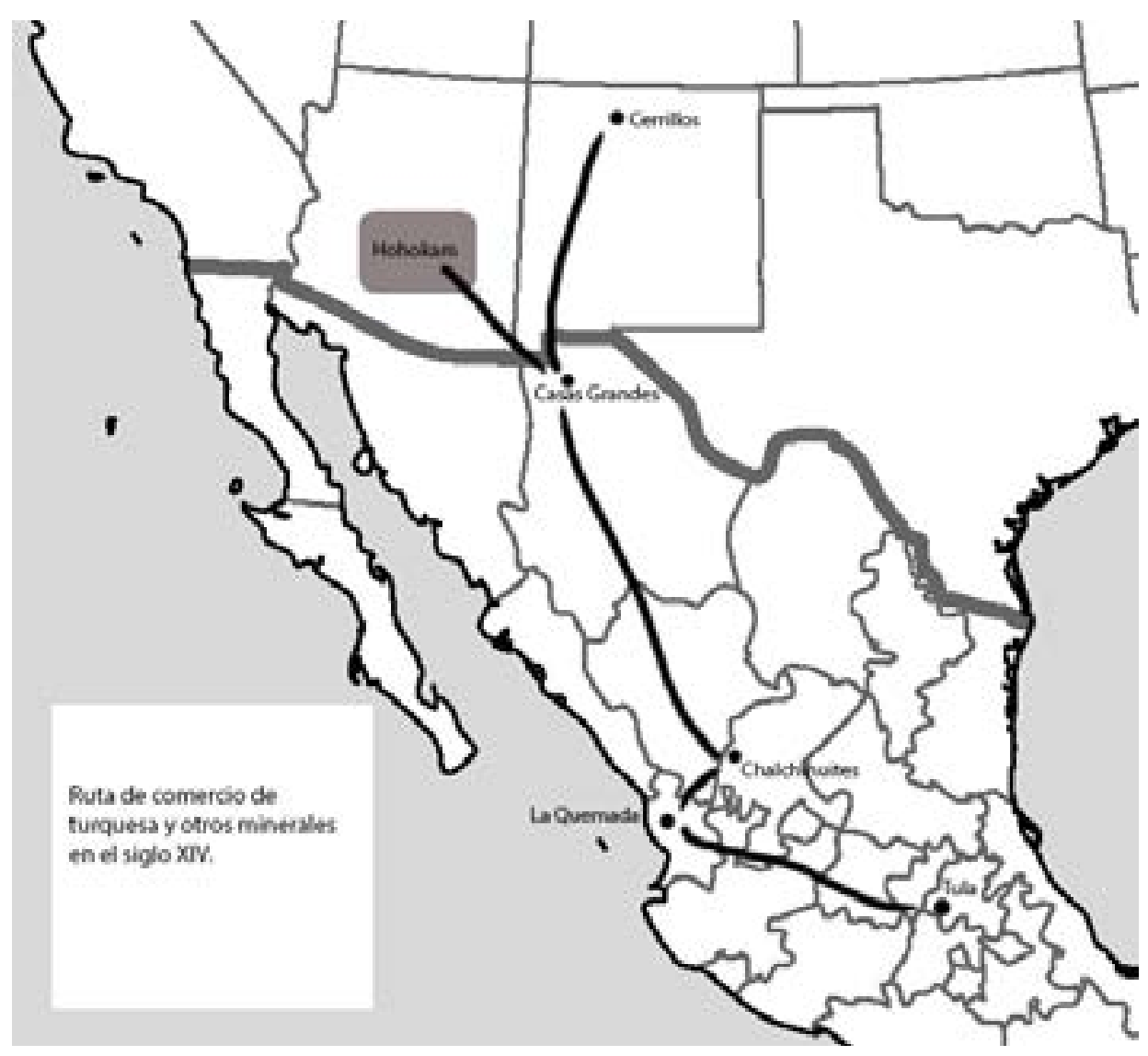


Otros grupos toltecas migraron hacia el sur, conquistaron Guatemala, a Nicaragua y Yucatán. Estos desplazamientos se explican por esa intensa necesidad que estos pueblos tenían de dominar las rutas y el comercio de las telas de algodón, miel, incienso de copal, y esclavos que se enviaban a Honduras quienes volvían con cacao, jade, y obsidiana y oro.

Quiero hacer aquí un señalamiento importante: David Harvey ha señalado como una condición indispensable para que tenga lugar el proceso de globalización la compresión espacio-tiempo, hecho que obliga a toda una reconceptualización del mundo. Ya que al ser arrasado el espacio por el tiempo necesariamente las concepciones del mundo se amplían y enriquecen.

Si bien es cierto que con el capitalismo se instaura una ruptura de fronteras espaciales esta ya tenía lugar en el siglo XIV y XV como hemos podido constatar no sólo en la complejidad de las rutas de comercio que vinculaban al sur con el norte de América. Por esto titulé el artículo con esta sugerencia: proceso de globalización en germen. Lo digo de esta manera porque el proceso de compresión espacio temporal se ha dado de manera gradual y es sólo hasta el día de hoy que reviste características muy intensas ${ }^{26}$.

Estos son hechos fundamentales que permiten plantear como una cuestión real y posible el vínculo entre estas dos áreas culturales: los Andes y el occidente y Mesoamérica con el Suroeste de los Estados Unidos y en consecuencia hablar del modo de producción americano.

\subsection{CONCLUSIONES}

1.-Lo primero que hay que decir acerca de estas reflexiones y como una conclusión general es que América toda estaba interconectada

26 David, Harvey, La condición de la posmodernidad. Investigación sobre sus orígenes del cambio sociocultural, Amorrortu, Buenos Aires, 1998. como puede verse en las rutas de comercio que fueron tanto marítimas como terrestres y que estos sistemas de intercambio dieron lugar a excedentes económicos que explican el florecimiento económico cultural y político de centros como el complejo comercial conocido como Mullo Teotihuacán primero y Tula posteriormente. Dieron lugar además al desarrollo de sociedades con Estados y clases sociales, como es el caso de incas, aztecas y mayas. $Y$ que fue un motor fundamental en la búsqueda y expansión de los distintos grupos, (reseña que he realizado en este artículo), ejemplificadora de este proceso; que fue fundamental en la consecución del excedente producto del tributo. Esta concepción que parte de una América conectada por rutas de comercio intenso, ideas, artefactos culturales, técnicas de cultivo, tratamiento de metales, etcétera, cuestiona profundamente desde la historia el llamado presente etnográfico estático sin un pasado que explique lo que el etnógrafo encuentra.

2.- Aunque en el artículo me interesa mostrar el vínculo existente entre América del Sur y el Occidente de México, no dejo de reseñar otras importantes rutas de comercio como la que tuvo lugar entre Tula en Mesoamérica y el Suroeste de los Estados Unidos en la búsqueda de la turquesa, importantísima desde el punto de vista ritual y ornamental de los nobles toltecas.

3.- En primer lugar los vínculos entre América de sur y el occidente de México están hoy por hoy muy documentados. Bien establecidas las rutas de comercio; los productos que se intercambiaban; el uso que se les daba. Esto quiere decir que se intercambiaban artículos, personas e informaciones de acuerdo a las necesidades. A este proceso lo he llamado proceso de globalización en ciernes, en tanto ya había una reconfiguración del espacio y del tiempo lograda por los navegantes. Ya se vislumbraba la compresión espacio 
temporal densa e intensa que se observa en la actualidad. Estos hechos generaron fenómenos de interculturalidad que demuestran que las culturas de América estaban profundamente interconectadas y comunicadas. A partir de esto se entiende cómo los nativos americanos cambiaron su entorno, la concepción del mundo y de la vida propia y la de los pueblos receptores de estos navegantes que rompieron fronteras espaciales. Éstas han sido siempre convenciones impuestas desde el poder porque en la práctica cultural de los seres humanos se definen y redefinen a lo largo de la historia.

El vínculo entre el sur y occidente de México es una relación que se ha explorado por varias vías:

a.- La tradición oral transmitida por los evangelizadores.

b.- Los templos o yácatas purépechas y las técnicas de pulido y colocación de las piedras.

c.- El trabajo de la metalurgia, oro, plata y cobre.

d.-Aunque cuestionado el parentesco lingüístico entre tarascos y quechuas y entre tarascos

y chibchas.

e.- Las tumbas de tiro y en especial la cerámica que acompaña a dichas tumbas.

f.- La hibridación de plantas presentes tanto en el norte como en el sur. Ejemplo palmario,

la presencia del maíz cacahuazintle mexicano tanto en Perú como en Colombia (con éste se elabora el pozole mexicano y la arepa colombiana).

g.- Deformaciones craneanas y mutilación dentaria tanto en uno como en otro lado.

h.- El jaguar como símbolo en las dos aéreas culturales.

i.- Todo este intenso intercambio fue posible gracias a los vientos y corrientes marítimas que facilitaron el viaje por la orilla en el transito sur a norte y un poco más alejado de ésta,

los viajes pudieron efectuarse en sentido inverso.

13.- La que he llamado la otra conexión, la existente entre el sur de México, Mesoamérica en particular y el suroeste de los Estados Unidos quiero sintetizar lo siguiente: la migración de sur a norte es una sola y esto puede verse en la presencia de artefactos culturales mesoaméricanos en el suroeste de los Estado Unidos, como por ejemplo:

a) El maíz, adaptado al entorno árido

b) La construcción de pirámides de tierra

c) El juego de pelota

d) La presencia de Tezcatlipoca y Quetzalcóatl

e) $Y$ de regreso a Mesoamérica la turquesa proveniente de Cerrillos Nuevo México y que fue tan importante desde el punto de vista ritual para los señores toltecas. Los hohokam a su vez adquirían conchas en la costa de California que a su vez intercambiaban por turquesa en Mogollón.

f) Chalchihuites fue importante centro cultural y de intercambio de la turquesa y intercambio de minerales de ahí su nombre junto con otros. Casa Grandes y La Quemada fueron los principales centros de comercio y de vínculo de Tula con el ran Suroeste de los Estados Unidos.

14.- Es por todo lo anterior que comparto la conceptualización de Eduardo Matos y Eduardo Corona de que la compleja red de relaciones y el intercambio comercial de los pueblos del norte y del sur de América permiten hablar de un modo de producción americano.

15.- Considero también que estos migrantes por mar, río o tierra arrasaron el espacio, 
destruyeron fronteras espaciales, contribuyeron a la expansión de su concepción del mundo, llevaron y trajeron "fondos de conocimiento" incrementado y re conceptualizaron también su propia dimensión del tiempo.

\section{REFERENCIAS BIBLILIOGRAFICAS}

BARTRA Roger, "El Modo de producción asiático en las sociedades pre capitalistas", en J.Chesnaux.et.al. El Modo de Producción asiático, Ed. Grijalbo, Col.70, No.42, México, 1969.

BELTRÁN, José, "Los pescadores de Punta Mita, Nayarit", Ponencia presentada en el 49

Congreso Internacional de Americanistas, Quito Ecuador, julio 1997.

CORONA, Eduardo, "La integración de los pueblos mesoamericanos", en H. Malmström Vincent, Geographical Origins Of The Tarascans, Geographical Review, Vol. 85, No. 1, January, 1995. Modo de producción americano, en Pueblos de América.org., (Revista virtual).2010.

DOBYNS, Henry,"Trails to Casa Grande", Casa Grande Valley,Histories, Casa Grande Valley Historical Society.

HOLSER, Dorothy, "Los orígenes andinos de la metalurgia del occidente de México", Boletín del Museo del Oro, № 42 de 1997Edición original: 2005-05-25Edición en la biblioteca virtual: 2005-05-25.

RIEFF ANAWALT, Patricia, "Traders of the Ecuador Littoral”, en Archaqueology, Vol., 50, No, 6, November-December, 1997, p 45.

ROSTWOROWSKI, María. "Pescadores, artesanos y mercaderes costeños en el Perú prehispánico", Revista del Museo Nacional, № 41,Lima, 1975.

PALERM, Ángel, “Una defensa del Modo asiático de Producción según Marx y Witfogel". UIA, Comunidad, No.23.Mexico, 1970, pp.31- 46.

CONRAD W, Geoffrey. y Demarest A. Arthur, Religión e imperio. Dinámica del Expansionismo azteca e inca, Alianza Editorial, Madrid,1988.

Craine, E. R., y R. C. Reindorp, (eds), The chronicles of Michoacán. Norman: University of Oklahoma Press.1970.

HAURY, W. Emil, "The Hohokam: Desert Farmers and Craftsmen, University of Arizona Press, Tucson, 1976.

HARVEY, David, La condición de la posmodernidad. Investigación sobre sus orígenes del cambio sociocultural, Amorrortu, Buenos Aires, 1998.

JIMÉNEZ MORENO, Wigberto, "Historia Antigua de la Zona Tarasca", ponencia presentada a la Cuarta Reunión de la Mesa Redonda: El Occidente de México. Sociedad Mexicana de Antropología, México.1946.

LUMBERAS, Luis Guillermo, Arqueología de la América Andina, Lima Perú, Editorial Batres, 1981.

Chavín de Huantar en el Nacimiento de la Civilización Andina, Lima, Ediciones Indea, Instituto Andino de Estudios Arqueológicos, 1989.

Visión arqueológica del Perú Milenario, Lima, Perú, Editorial Batres, 1990.

MARCOS, Jorge G, Los pueblos navegantes del Ecuador prehispánico, ediciones ABYA-YALA, Quito, 2005.

MATOS M, Eduardo, "Mesoamérica" en Historia Antigua de México,Vol., I., pp.49- 73, México, 1994. 
MURRA V, John, El mundo andino población, medio ambiente y economía, Pontificia Universidad Católica del Perú, Instituto de Estudio Peruanos, Perú, 2002.

OLIVEROS, Arturo, Hacedores de tumbas en el Opeño, Jacona, Michoacán, El Colegio de Michoacán, México, 2004.

PAREDES M, Carlos, "Sistemas de intercambio en el Estado Tarasco: Notas para su estudio", en Origen y desarrollo de la civilización en el Occidente de México, Brigette Bohem de Lameiras y Phil C. Weigand (coord.), México, El Colegio de Michoacán.

SWADESH, Mauricio, "Un nexo prehistórico entre quechua y tarasco", en Anales, Instituto Nacional de Antropología e Historia, Época séptima, Tomo 1, 1968-1969, Mexico, p.49.

ROJAS,RABIELA, La agricultura chinampera compilación histórica, núm. 7 de la colección Cuadernos Universitarios, Serie Agronomía, Universidad Autónoma de Chapingo, Dirección de Difusión Cultural, 1983.

TORRES MONTES, Luis y Franco Velásquez, Francisca, "La metalurgia tarasca. Producción y uso de los metales en Mesoamérica", en Temas Mesoamericanos, Sonia Lombardo y Enrique Nalda, (coord.), México, Colección Varios, Instituto Nacional de Antropología e Historia, 1996.

VÉLEZ IBÁÑEZ, Carlos, Border Visions, Mexican Cultures of the Southwest United States, Tucson, The University of Arizona Press, 1996.

VORGELEGT VON SARAH ALBIEZ, Wieck, Contactos exteriores del Estado Tarasco: influencias desde dentro y fuera de Mesoamérica, Inaugural-Dissertation zur Erlangung der Doktorwürde de Philosophischen FakultätDer
Rheinischen Friedrich-Wilhelms- Universität zu Bonn, Boon.2011. 